\title{
A Review of Additive Manufacturing
}

\author{
Kaufui V. Wong and Aldo Hernandez \\ Department of Mechanical and Aerospace Engineering, University of Miami, Coral Gables, FL 33146, USA
}

Correspondence should be addressed to Kaufui V. Wong, kwong@miami.edu

Received 29 May 2012; Accepted 17 June 2012

Academic Editors: N. Anifantis and F. Findik

Copyright ( $) 2012$ K. V. Wong and A. Hernandez. This is an open access article distributed under the Creative Commons Attribution License, which permits unrestricted use, distribution, and reproduction in any medium, provided the original work is properly cited.

\begin{abstract}
Additive manufacturing processes take the information from a computer-aided design (CAD) file that is later converted to a stereolithography (STL) file. In this process, the drawing made in the CAD software is approximated by triangles and sliced containing the information of each layer that is going to be printed. There is a discussion of the relevant additive manufacturing processes and their applications. The aerospace industry employs them because of the possibility of manufacturing lighter structures to reduce weight. Additive manufacturing is transforming the practice of medicine and making work easier for architects. In 2004, the Society of Manufacturing Engineers did a classification of the various technologies and there are at least four additional significant technologies in 2012. Studies are reviewed which were about the strength of products made in additive manufacturing processes. However, there is still a lot of work and research to be accomplished before additive manufacturing technologies become standard in the manufacturing industry because not every commonly used manufacturing material can be handled. The accuracy needs improvement to eliminate the necessity of a finishing process. The continuous and increasing growth experienced since the early days and the successful results up to the present time allow for optimism that additive manufacturing has a significant place in the future of manufacturing.
\end{abstract}

\section{Rapid Prototyping}

The first form of creating layer by layer a three-dimensional object using computer-aided design (CAD) was rapid prototyping, developed in the 1980's for creating models and prototype parts. This technology was created to help the realization of what engineers have in mind. Rapid prototyping is one of the earlier additive manufacturing (AM) processes. It allows for the creation of printed parts, not just models. Among the major advances that this process presented to product development are the time and cost reduction, human interaction, and consequently the product development cycle [1], also the possibility to create almost any shape that could be very difficult to machine. However, at the present time it is not yet adopted in the manufacturing sector, but scientists, medical doctors, students and professors, market researchers, and artists use it [2-4]. With rapid prototyping, scientists and students can rapidly build and analyze models for theoretical comprehension and studies. Doctors can build a model of a damaged body to analyze it and plan better the procedure, market researchers can see what people think of a particular new product, and rapid prototyping makes it easier for artists to explore their creativity.

The steps involved in product development using rapid prototyping are shown in Figure 1. Here, it can be seen that creating models faster save a lot of time and there is the possibility of testing more models.

At the present time, the technologies of rapid prototyping are not just used for creating models, with the advantages in plastic materials it has been possible to create finished products, of course at the beginning they were developed to expand the situations tested in the prototyping process [5]. Nowadays, these technologies have other names like 3D printing, and so forth, but they all have the origins of rapid prototyping [2, 6]. According to Wohler's report 2011 the 


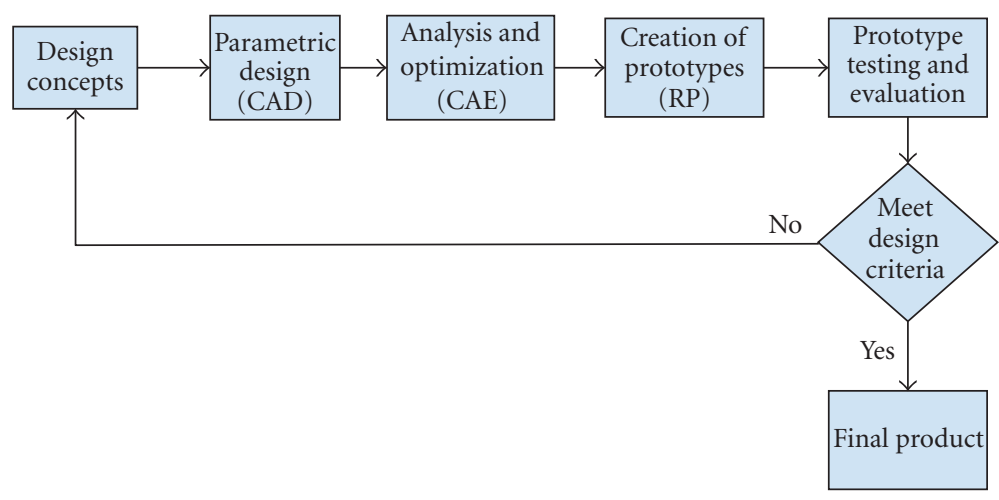

Figure 1: Product development cycle [2].

growth rate for 2010 was $24.1 \%$. The compound annual growth rate for the industry's history, until 2010, is 26.2 percent $[7,8]$. This growth shown in Figure 2.

In addition, it is important to notice that rapid manufacturing became possible by other technologies, which are computer-aided design (CAD), computer-aided manufacturing (CAM), and computer numerical control (CNC). This three technologies combined together made possible the printing of three-dimensional objects $[2,5,11]$.

Rapid prototyping is still not the best solution for all cases, in some cases CNC machining processes still need to be used. Parts dimension could be larger than available additive manufacturing printers [8]. Materials for rapid prototyping are still limited. It is clear that at least it is possible to print metals and ceramics but not all commonly used manufacturing materials [11].

In Figure 3, there is an overview of the different additive manufacturing processes that are going to be further discussed. Here in this figure adapted from [11], the criterion used is to classify these processes into liquid base, solid based, and powder based. The processes included in this review are considered the most relevant in the past, and promising for the future of the industry. The processes considered are stereolithography (SL), Polyjet, fused deposition modeling (FDM), laminated object manufacturing (LOM), 3D printing (3DP), Prometal, selective laser sintering (SLS), laminated engineered net shaping (LENS), and electron beam melting (EBM). The liquid-and powder-based processes seem more promising than solid-based processes of which LOM is the predominant one today. In 2004 [11], EBM, Prometal, LENS, and Polyjet were nonexistent.

These technologies were first created to produce models, but they have expanded since then. In the chart is presented a survey made by Wohlers in which 24 manufacturers participated and so did 65 services of $5000+$ users and costumers. In Figure 4 is shown the amount of responses received by these companies [12].

\section{Stereolithography}

Stereolithography (SL), developed by 3D Systems, Inc., was the first and is most widely used process of rapid prototyping, so, in the past the two terms were used synonymously. This is

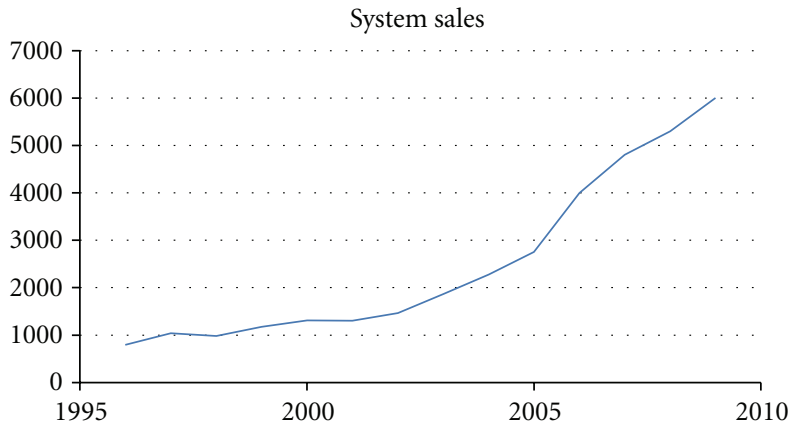

FIgURE 2: Growth of rapid prototyping [9]. Source. Wohler's report 2010 adapted from [10].

a liquid-based process that consists in the curing or solidification of a photosensitive polymer when an ultraviolet laser makes contact with the resin. The process starts with a model in a CAD software and then it is translated to a STL file in which the pieces are "cut in slices" containing the information for each layer. The thickness of each layer as well as the resolution depend on the equipment used. A platform is built to anchor the piece and supporting the overhanging structures. Then the UV laser is applied to the resin solidifying specific locations of each layer. When the layer is finished the platform is lowered and finally when the process is done the excess is drained and can be reused [2, 5, 11]. A newer version of this process has been developed with a higher resolution and is called microstereolithography. This process that has a layer thickness of less than $10 \mu \mathrm{m}$ can be achieved [13]. In Figure 5 are shown the basic parts of a stereolithography machine.

The basic principle of this process is the photopolymerization, which is the process where a liquid monomer or a polymer converts into a solidified polymer by applying ultraviolet light which acts as a catalyst for the reactions; this process is also called ultraviolet curing. It is also possible to have powders suspended in the liquid like ceramics [14].

There are errors induced to the final piece from the process of stereolithography. One is overcuring, which occurs to overhang parts because there is no fusing with a bottom layer. Another is the scanned line shape, which is introduced 


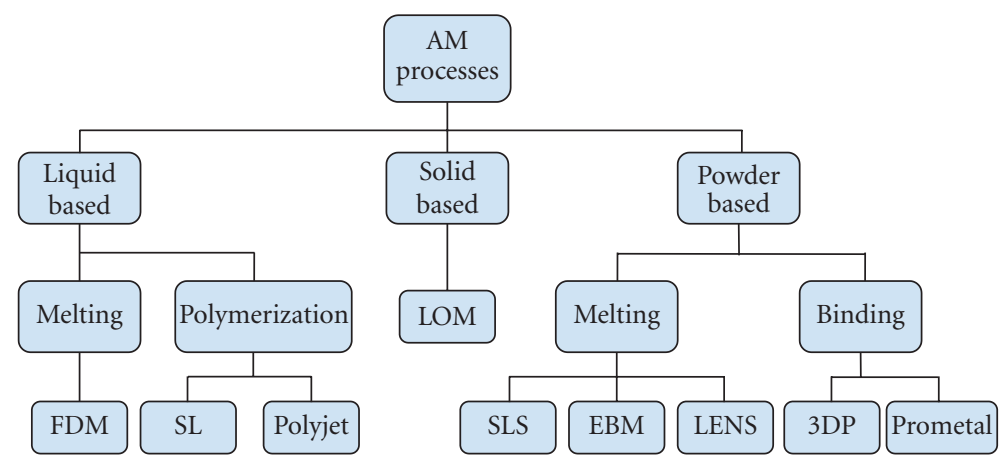

FIgURE 3: Three-dimensional printing processes. Adapted from [11].

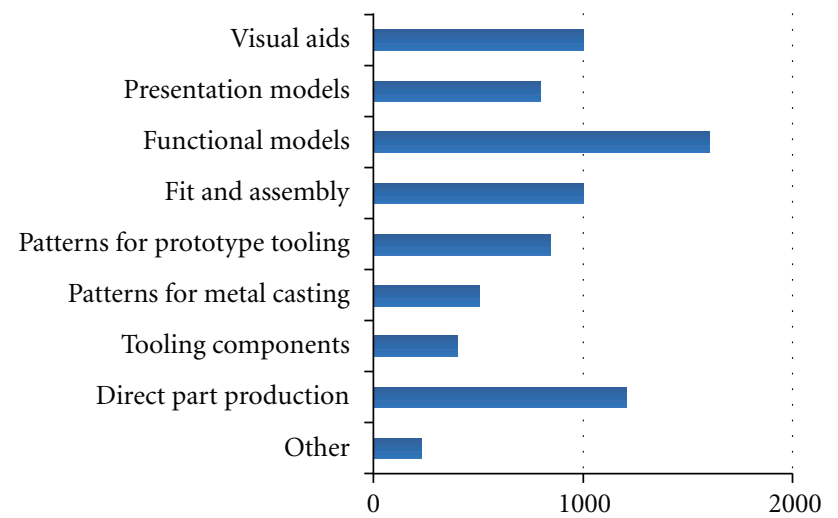

FIGURE 4: Different usage for additive manufacturing printing processes [12].

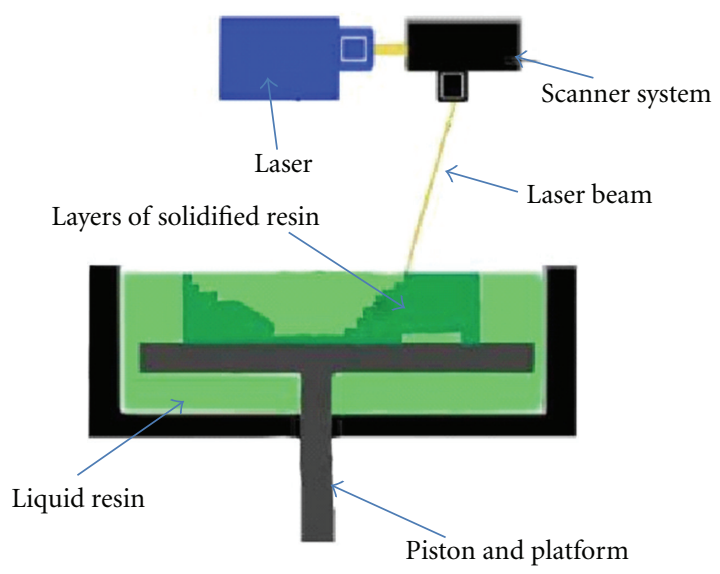

Figure 5: Stereolithography.

by the scanning process. Because the resin is a high-viscosity liquid the layer thickness is variable and this introduces an error in the border position control. Another error caused could be if the part needed to have a surface finished process that is normally done by hand [21]. All these errors are minimized in equipments of high quality.

There is the possibility of using different materials while building a piece; this process is called multiple material stereolithography. In order to print with different materials all the resin has to be drained and filled with the new material when the process reach the layer where the change is going to take place. This must occuer even if the first material is going to be used again because is only possible to print consecutive layers. resin. In the software a scheduling process has to be specified [22].

\section{The STL File}

The STL file was created in 1987 by 3D Systems Inc. when they first developed the stereolithography, and the STL file stands for this term. It is also called Standard Tessellation Language. There are other types of files, but the STL file is the standard for every additive manufacturing process. The STL file creation process mainly converts the continuous geometry in the CAD file into a header, small triangles, or coordinates triplet list of $x, y$, and $z$ coordinates and the normal vector to the triangles. This process is inaccurate and the smaller the triangles the closer to reality $[2,13,23]$. The interior and exterior surfaces are identified using the right-hand rule and vertices cannot share a point with a line. Additional edges are added when the figure is sliced. The slicing process also introduces inaccuracy to the file because here the algorithm replaces the continuous contour with discrete stair steps [23]. To reduce this inaccuracy, the technique for a feature that has a small radius in relation to the dimension of the part is to create STL files separately and to combine them later. The dimension in $z$ direction should be designed to have a multiple of the layer thickness value [21]. In Figure 6 is shown the position of the STL file creation in the data flow of a rapid prototyping process. In Figure 7 is shown the data flow in the STL file creation software.

Other types of files are stereolithography contour (SLC) and SLI from 3D Systems, CLI from EOS, Hewlett-Packard graphics language (HPGL) from Hewlett-Packard, stereolithography contour from Stratasys, and F\&S from Fockele and Schwarze and initial graphics exchange specifications (IGES) [13].

\section{3DP}

3DP process is a MIT-licensed process in which water-based liquid binder is supplied in a jet onto a starch-based powder to print the data from a CAD drawing. The powder particles 


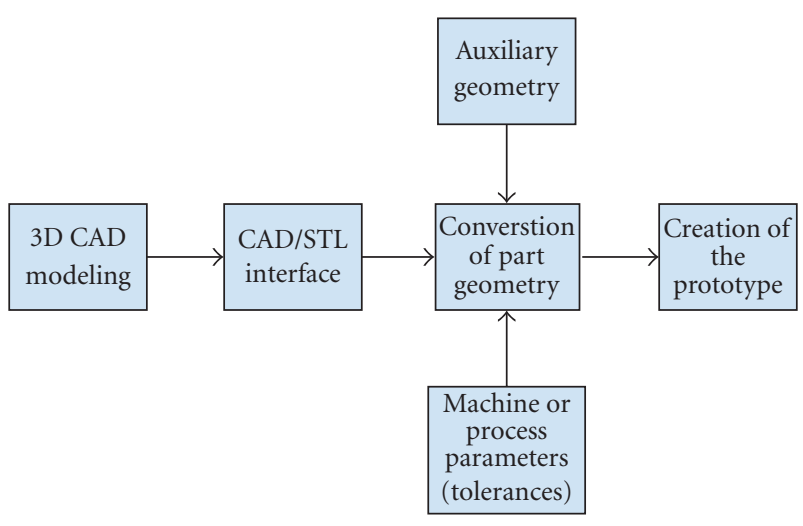

FIgURE 6: Data flow in rapid prototyping [2].

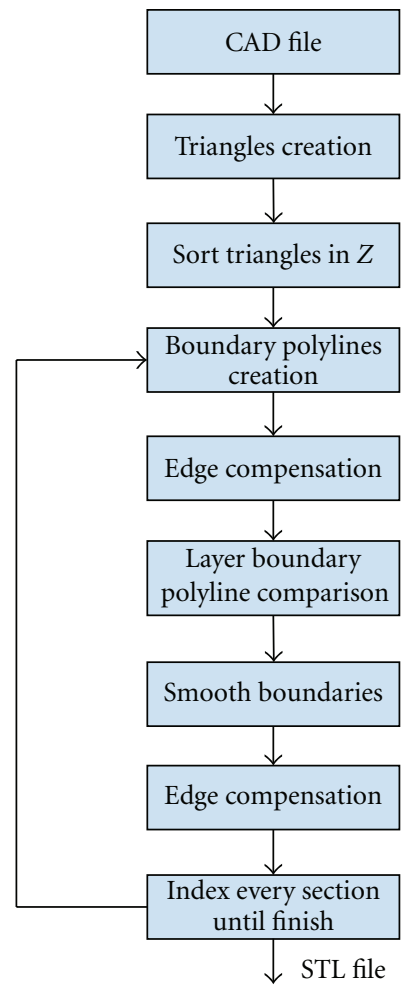

Figure 7: Data flow in STL file creation [2].

lie in a powder bed and they are glued together when the binder is jetted. This process is called 3DP because of the similarity with the inkjet printing process that is used for two-dimensional printing in paper. This process can handle a high variety of polymers $[5,13]$.

\section{Fused Deposition Modeling}

Fused deposition modeling (FDM) is an additive manufacturing process in which a thin filament of plastic feeds a machine where a print head melts it and extrude it in a thickness typically of $0.25 \mathrm{~mm}$. Materials used in this process are polycarbonate (PC), acrylonitrile butadiene styrene (ABS), polyphenylsulfone (PPSF), PC-ABS blends, and PC-ISO, which is a medical grade PC. The main advantages of this process are that no chemical post-processing required, no resins to cure, less expensive machine, and materials resulting in a more cost effective process $[2,5]$. The disadvantages are that the resolution on the $z$ axis is low compared to other additive manufacturing process $(0.25 \mathrm{~mm})$, so if a smooth surface is needed a finishing process is required and it is a slow process sometimes taking days to build large complex parts. To save time some models permit two modes; a fully dense mode and a sparse mode that save time but obviously reducing the mechanical properties [24]. In Figure 8 is shown the basics fused deposition modeling process.

\section{Prometal}

Prometal is a three-dimensional printing process to build injection tools and dies. This is a powder-based process in which stainless steel is used. The printing process occurs when a liquid binder is spurt out in jets to steel powder. The powder is located in a powder bed that is controlled by build pistons that lowers the bed when each layer is finished and a feed piston that supply the material for each layer. After finishing, the residual powder must be removed. When building a mold no postprocessing is required. If a functional part is being built, sintering, infiltration, and finishing processes are required $[5,11]$. In the sintering process, the part is heated to $350^{\circ} \mathrm{F}$ for 24 hour hardening the binder fusing with the steel in a $60 \%$ porous specimen. In the infiltration process, the piece is infused with bronze powder when they are heated together to more than $2000^{\circ} \mathrm{F}$ in an alloy of $60 \%$ stainless steel and $40 \%$ bronze [25-27]. The same process, but with different sintering temperatures and times, has been used with other materials like a tungsten carbide powder sintered with a zirconium copper alloy for the manufacturing of rocket nozzles; these parts have better properties than $\mathrm{CNC}$ machined parts of the same material [28].

\section{Selective Laser Sintering}

This is a three-dimensional printing process in which a powder is sintered or fuses by the application of a carbon dioxide laser beam. The chamber is heated to almost the melting point of the material. The laser fused the powder at a specific location for each layer specified by the design. The particles lie loosely in a bed, which is controlled by a piston, that is lowered the same amount of the layer thickness each time a layer is finished. This process offers a great variety of materials that could be used: plastics, metals, combination of metals, combinations of metals and polymers, and combinations of metals and ceramics $[13,29$, 30]. Examples of the polymers that could be used are acrylic styrene and polyamide (nylon), which show almost the same mechanical properties as the injected parts [29, 31]. It is also possible to use composites or reinforced polymers, that is, polyamide with fiberglass. They also could be reinforced with metals like copper. For metals, a binder is necessary. This could be a polymer binder, which will be later removed by 


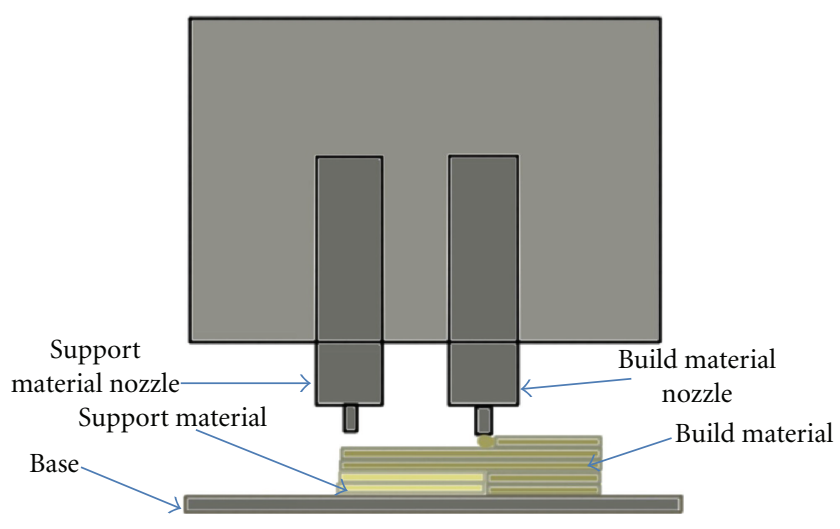

Figure 8: Fused deposition modeling.

heating or a mix of metals with very different melting point $[29,31,32]$. Parts of alumina with high strength can be built with polyvinyl alcohol, which is an organic binder [5]. The main advantages of this technology are the wide range of materials that can be used. Unused powder can be recycled. The disadvantages are that the accuracy is limited by the size of particles of the material, oxidation needs to be avoided by executing the process in an inert gas atmosphere and for the process to occur at constant temperature near the melting point. This process is also called direct metal laser sintering.

\section{Electron Beam Melting}

A process similar to SLS is electron beam melting (EBM). This process is relatively new but is growing rapidly. In this process, what melts the powder is an electron laser beam powered by a high voltage, typically 30 to $60 \mathrm{KV}$. The process takes place in a high vacuum chamber to avoid oxidation issues because it is intended for building metal parts. Other than this, the process is very similar to SLS. EBM also can process a high variety of prealloyed metals. One of the future uses of this process is the manufacturing in outer space $[33,34]$, since it is all done in a high vacuum chamber.

\section{Laser Engineered Net Shaping}

In this additive manufacturing process, a part is built by melting metal powder that is injected into a specific location. It becomes molten with the use of a high-powered laser beam. The material solidifies when it is cooled down. The process occurs in a closed chamber with an argon atmosphere. This process permits the use of a high variety of metals and combination of them like stainless steel, nickelbased alloys, titanium-6 aluminium-4 vanadium, tooling steel, copper alloys, and so forth. Alumina can be used too. This process is also used to repair parts that by other processes will be impossible or more expensive to do. One problem in this process could be the residual stresses by uneven heating and cooling processes that can be significant in highprecision processes like turbine blades repair [5, 13, 35-37]. Figure 9 is an illustration of how the part is made in this process.

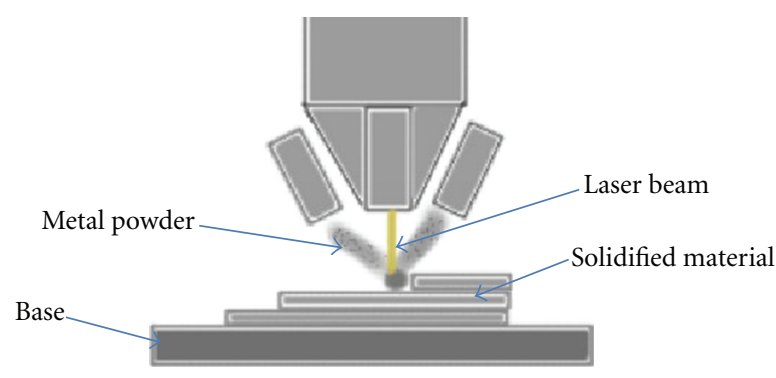

FIGURE 9: Laser engineered net shaping.

\section{Laminated Object Manufacturing}

Laminated Object Manufacturing (LOM) is a process that combines additive and subtractive techniques to build a part layer by layer. In this process the materials come in sheet form. The layers are bonded together by pressure and heat application and using a thermal adhesive coating. A carbon dioxide laser cuts the material to the shape of each layer given the information of the 3D model from the CAD and STL file. The advantages of this process are the low cost, no post processing and supporting structures required, no deformation or phase change during the process, and the possibility of building large parts. The disadvantages are that the fabrication material is subtracted thus wasting it, low surface definition, the material is directional dependent for machinability and mechanical properties, and complex internal cavities are very difficult to be built. This process can be used for models with papers, composites, and metals $[2,5,38]$.

\section{Polyjet}

This is an additive manufacturing process that uses inkjet technologies to manufacture physical models. The inkjet head moves in the $x$ and $y$ axes depositing a photopolymer which is cured by ultraviolet lamps after each layer is finished. The layer thickness achieved in this process is $16 \mu \mathrm{m}$, so the produced parts have a high resolution. However, the parts produced by this process are weaker than others like stereolithography and selective laser sintering. A gel-type polymer is used for supporting the overhang features and after the process is finished this material is water jetted. With this process, parts of multiple colors can be built $[9,39,40]$.

\section{Applications}

12.1. Lightweight Machines. With additive manufacturing technologies it is possible to manufacture lightweight parts. In the automotive and aerospace industry the main goal is to make the lightest practical car or aircraft while securing safety. Additive manufacturing technologies have enabled the manufacture of complex cross sectional areas like the honeycomb cell [41] or every other material part that contains cavities and cut-outs which reduce the weight-strength relation. It is possible to create lightweight structures; they are methods to get a shape that have a minimum weight like 
the hanging method and the soap film method [42]. The hanging method and the soap fill method produce a very difficult form of a structure which has been used for civil construction, but with additive manufacturing it is possible to create structural parts for machines using the shape described by these methods and reducing the total weight. Selective laser sintering, and electron beam are now used in the aircraft and aerospace industries. Engineers perform design within the manufacturing constrains but this process expands the limits. With SLS and EBM, the limit will be the engineer's imagination. They open a whole new dimension of possible designs with almost any prealloyed metal powder [37]. With the traditional process these complex shape structures will be expensive to do if at all possible. With additive manufacturing printing technologies like selective laser sintering or electron beam melting, hollow structures, which are less expensive than a solid one, can be made since less material is used.

12.2. Architectural Modeling. Creating an architectural model can be very difficult for architects. Architects usually build their models with hand techniques, but when complex models are on their minds making a physical model can be a very hard task. Modeling is very important for the architects to study the models and their functionality. They are also needed for architects to explain them to their customers and convince them to make the project a reality [43]. Additive manufacturing technologies can provide architects a very powerful tool for their business, by being able to create a physical model faster without worrying about the complexity of their design. It also achieves a better resolution than other processes used in architecture. Architects work with CAD software, so there is no need for them to adapt to anything because the STL file is created from a CAD file. Stereolithography is a process very suitable for the architectural modeling because of the materials used and the printing resolution [34-47].

12.3. Medical Applications. Additive manufacturing printing technologies have vast applications in the medical world. They are transforming the practice of medicine through the possibilities of making rapid prototypes and very high quality bone transplants and models of damaged bone of the patients for analysis. Additive manufacturing printing methods permit to scan and build a physical model of defective bones from patients and give doctors a better idea of what to expect and plan better the procedure, this will save cost and time and help achieve a better result [48, 49]. Bone transplants now can be done by printing them and additive manufacturing methods make it possible to have a transplant that is practically identical to the original. Because of the limitless form or shape of what could be built, doctors have the option to create a porous-controlled material that will permit osteoconductivity or to create a precise metal transplant identical to the original depending on the bone to be replaced [50-52]. Characteristics of the transplants such as density, pore shape and size, and pore interconnectivity are important parameters that will manipulate tissue ingrowth and mechanical properties of the implant bone. The mechanical strength of these implants are three to five times higher than others produced by other processes and the possibility of inflammation caused by microdebris that breaks during the procedure is reduced [45]. Additive manufacturing is a very good tool for dentists because they can easily build a plaster model of a patient's mouth or replace the teeth, which have a unique form with process like stereolithography, selective laser sintering and electron beam melting [53-55].

According to PC Magazine [54], an 83-year-old Belgian woman became the first-ever person to receive a transplant jawbone tailor-made for her face using a 3D printer and the surgery time and recovery were a lot less than other patients that received the same procedure. The shapes of bones differ too much between each person and additive manufacturing printing produces transplants that fit better, and are easier to insert and secure, reducing the time for the procedure and produce a better cosmetic result $[55,56]$.

Stereolithography is being used to manufacture prosthetic sockets. By using this technology to ensure that the form of the socket adapt better to the patient while being more cost-effective than hand or machined methods [57]. Not only hard parts like bones can be produced, also it is possible to print cells in a $3 \mathrm{D}$ array that with the possibility of printing complex shapes and arrays human tissue can be printed [58-61]. This technology will help patients that have lost tissue in accidents or from other reasons to recover faster and with better cosmetic results. In addition $3 \mathrm{D}$ cell printing technologies offer the possibility of printing artificial blood vessels that can be used in the coronary bypass surgery or any other blood vessel procedure or diseases, like cardiovascular defects and medical therapy [62-64]. The application of this printed blood vessels is in the future. Research in this area, also called bioprinting organs, will eventually lead to printed organs, but this could take 20 years until someone achieves it [65].

Cell printing is not limited to print human tissue; it is also used in the field of molecular electronics. The precision of high-resolution processes like nanolithography and photolithography permits the creation of biochips and biosensors $[63,66,67]$.

12.4. Improving the Manufacturing of Fuel Cells. Additive manufacturing technologies can be used in processes that require a very precise thin film of a certain material. In the manufacture of polymer electrolyte membrane fuel cells (PEMFCs), it is necessary to precisely deposit a very thin layer of platinum, needed for the oxidation and reduction reactions, with high utilization efficiency of the platinum. This could be critical for taking this technology to the masses. One of the other processes used is screen printing, but this process is done by hand and compromises the uniformity and time efficiency. The process is greatly improved by using the $3 \mathrm{D}$ printing process to deposit the layer of platinum. In Figure 10, there is a comparison between the processes. The inkjet printing method is 4 to 5 times faster than screen printing [15]. 

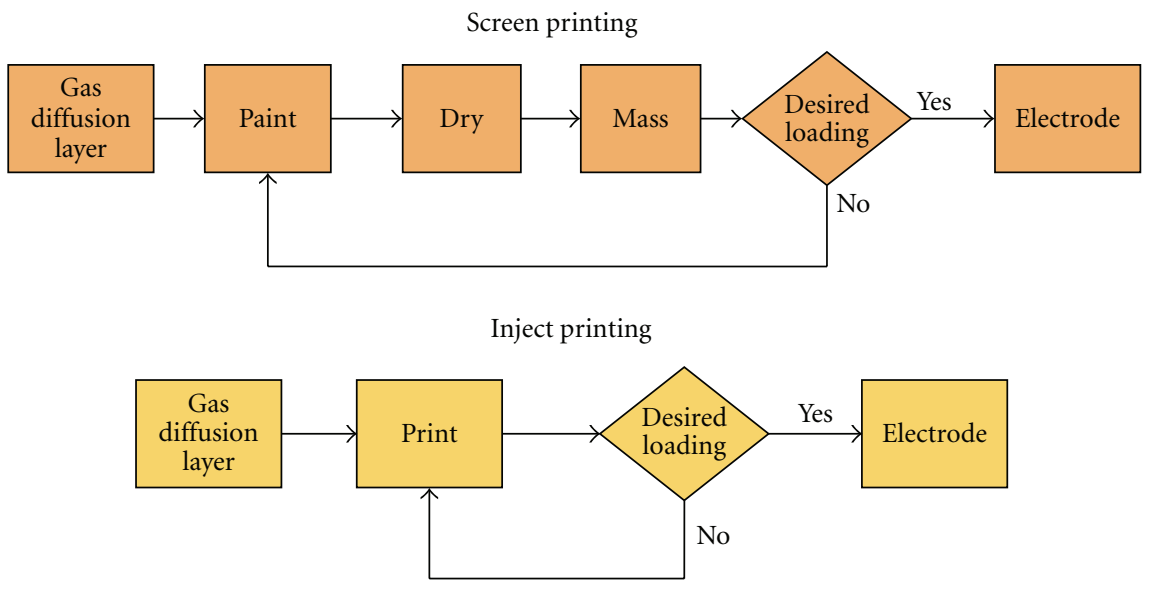

Figure 10: Screen printing compared to inkjet Printing [15].

12.5. Additive Manufacturing in Art. Additive manufacturing technologies are a very powerful tool to artist in the fashion, furniture, and lightning industry given the possibility of virtually manufacturing the most complex form imaginable. There are companies that manufacture furnishing complements, lightning, and accessories including clothes using SLS [68-70].

12.6. Additive Manufacturing for Hobbyist. Additive manufacturing technologies are reaching nonindustrial users. This revolution started in 2007 with printers that could be as low as $\$ 500$ using a variant of the fused deposition modeling process. However, these low-cost printers are mostly sold as do-it-yourself (DIY) projects, so, technical ability on the part of the users is required. However, these days with larger companies entering the business 3D printers are closer to reaching the masses. At this time, plastics and edible materials like chocolate materials are only available [71-73]. Users can use CAD software normally used by engineers. Easier ones for hobbyists are available which can be used for design. There are many apps that hobbyists can make 3D models and print them using a 3D printer [74].

12.7. Strength Comparison. Studies have been made to analyze the properties of the product in each process. Kim and $\mathrm{Oh}$ [16] compared the properties of nonmetal additive manufacturing processes. They tested the specimens in the building direction and perpendicular to the building direction and they found very little influence in the building direction in 3DP but an enormous influence in LOM [70]. Figure 11 is a comparison of the strength for LOM, Polyjet, SL, SLS, FDM, and 3DP.

The strength of the material produced by Prometal, EBM, SLS, and LENS is compared in Figure 12. The studies were made by [17-20].

\section{Discussion and Conclusion}

In this paper article is discussed the early versions of additive manufacturing for making fast prototypes that was initiated

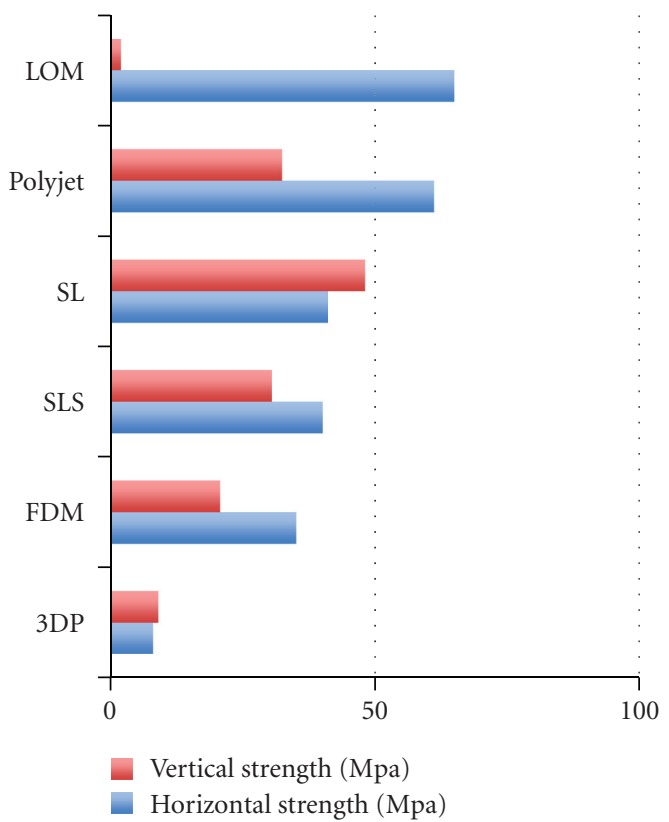

FIGURE 11: Tensile strength of various 3D printing processes adapted from [16].

by the necessity of speeding the process in model development and shortening the time between product development and market placement. Additive manufacturing processes take the information from a CAD file that is later converted to an STL file. In this process, the drawing made in the CAD software is approximated by triangles and sliced containing the information of each layer that is going to be printed. There is also a discussion of the relevant additive manufacturing processes and their applications and a review of how the parts are made using these additive manufacturing processes. The continuous and increasing growth experienced since the early days and the successful results up to date, there is optimism that additive manufacturing has a significant place in the future of manufacturing. 


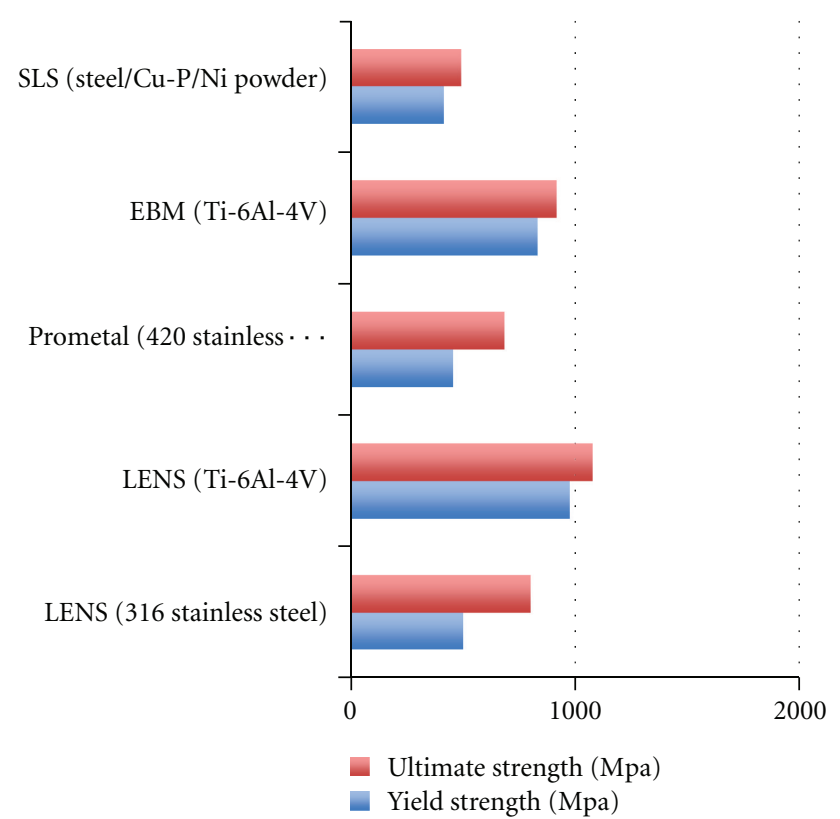

FIGURE 12: Tensile strength of various 3D printing processes [17$20]$.

In 2004, the Society of Manufacturing Engineers did a classification of the various technologies [11], but there are at least four additional significant technologies in 2012.

Additive manufacturing technologies have been welcomed in the aerospace industry because of the possibility to manufacture lighter structures to reduce weight, which is the common goal of aircraft and spacecraft designers. In the automotive industry, additive manufacturing is advantageous also in reproducing difficult-to-find parts, for example, parts for classic cars. Additive manufacturing is transforming the practice of medicine; now it is possible to have a precise model of a bone before a surgery and the possibility of creating an accurate transplant, no matter how complex its form is. Additive manufacturing is making work easier for architects, who now can print the 3D models of whatever complex shape for a civil project they have in mind. In addition, studies are reviewed which were about the strength of products made in additive manufacturing processes. Review has been presented of studies considering nonmetal material processes and metal material processes in which a comparison of strength of the products was made by the various processes. However, there is still a lot of work and research to be accomplished before additive manufacturing processes become the standard in the manufacturing industry because not every commonly used manufacturing material can be handled. The accuracy needs improvement to eliminate the necessity of a finishing process and to be able to produce parts that require the highest levels of precision.

\section{References}

[1] S. Ashley, "Rapid prototyping systems," Mechanical Engineering, vol. 113, no. 4, p. 34, 1991.
[2] R. Noorani, Rapid Prototyping-Principles and Applications, John Wiley \& Sons, 2006.

[3] J. Flowers and M. Moniz, "Rapid prototyping in technology education,” Technology Teacher, vol. 62, no. 3, p. 7, 2002.

[4] C. K. Chua, S. M. Chou, S. C. Lin, K. H. Eu, and K. F. Lew, "Rapid prototyping assisted surgery planning," International Journal of Advanced Manufacturing Technology, vol. 14, no. 9, pp. 624-630, 1998.

[5] K. Cooper, Rapid Prototyping Technology, Marcel Dekker, 2001.

[6] A. Kochan, "Rapid growth for rapid prototyping," Assembly Automation, vol. 17, no. 3, pp. 215-217, 1997.

[7] T. Wohlers, Wohlers Report 2011, Wholers Associates, 2011.

[8] T. Wohlers, "Additive Manufacturing Advances," Manufacturing Engineering, vol. 148, no. 4, pp. 55-56, 2012.

[9] T. Wohlers, Wohlers Report 2010, Wholers Associates, 2010.

[10] T. Grimm, User's Guide to Rapid Prototyping, Society of Manufacturing Engineers, 2004.

[11] P. P. Kruth, "Material incress manufacturing by rapid prototyping techniques," CIRP Annals-Manufacturing Technology, vol. 40, no. 2, pp. 603-614, 1991.

[12] T. Wohlers, Wohlers Report 2009, Wholers Associates, 2009.

[13] J. W. Halloran, V. Tomeckova, S. Gentry et al., "Photopolymerization of powder suspensions for shaping ceramics," Journal of the European Ceramic Society, vol. 31, no. 14, pp. 2613-2619, 2011.

[14] D. T. Pham and C. Ji, "Design for stereolithography," Proceedings of the Institution of Mechanical Engineers, vol. 214, no. 5, pp. 635-640, 2000.

[15] A. D. Taylor, E. Y. Kim, V. P. Humes, J. Kizuka, and L. T. Thompson, "Inkjet printing of carbon supported platinum 3D catalyst layers for use in fuel cells," Journal of Power Sources, vol. 171, no. 1, pp. 101-106, 2007.

[16] G. D. Kim and Y. T. Oh, "A benchmark study on rapid prototyping processes and machines: quantitative comparisons of mechanical properties, accuracy, roughness, speed, and material cost," Proceedings of the Institution of Mechanical Engineers, vol. 222, no. 2, pp. 201-215, 2008.

[17] J. P. Kruth, X. Wang, T. Laoui, and L. Froyen, "Lasers and materials in selective laser sintering," Assembly Automation, vol. 23, no. 4, pp. 357-371, 2003.

[18] L. Facchini, E. Magalini, P. Robotti, and A. Molinari, "Microstructure and mechanical properties of Ti-6Al-4V produced by electron beam melting of pre-alloyed powders," Rapid Prototyping Journal, vol. 15, no. 3, pp. 171-178, 2009.

[19] R. Shivpuri, X. Cheng, K. Agarwal, and S. Babu, "Evaluation of 3D printing for dies in low volume forging of 7075 aluminum helicopter parts," Rapid Prototyping Journal, vol. 11, no. 5, pp. 272-277, 2005.

[20] Y. Xiong, Investigation of the laser engineered net shaping process for nanostructured cermets [ProQuest Dissertations], University of California, 2009.

[21] H. Kim, C. Jae-Won, and R. Wicker, "Scheduling and process planning for multiple material stereolithography," Rapid Prototyping Journal, vol. 16, no. 4, pp. 232-240, 2010.

[22] M. Szilvœi-Nagy and G. Mátyási, "Analysis of STL files," Mathematical and Computer Modelling, vol. 38, no. 7-9, pp. 945-960, 2003.

[23] C. Iancu, D. Iancu, and A. Stamcioiu, "From Cad model to 3D print via "STL" file format," http://www.utgjiu.ro/rev_ mec/mecanica/pdf/2010-01/13_Catalin\%20Iancu.pdf.

[24] S. Morvan, R. Hochsmann, and M. Sakamoto, "ProMetal RCT(TM) process for fabrication of complex sand molds and sand cores," Rapid Prototyping, vol. 11, no. 2, pp. 1-7, 2005. 
[25] R. C. T. ProMetal, "ProMetal RCT rapid prototyping and digital sand casting services," 2010, http://www.youtube.com/ watch? $\mathrm{v}=\mathrm{Z} 8 \mathrm{MaVaqNr} 3 \mathrm{U}$.

[26] Ex One, "3D metal printing," 2010, http://www.youtube.com/ watch? $v=i 6 P x 6 R S L 9 A c \& f e a t u r e=$ related.

[27] D. W. Lipke, Y. Zhang, Y. Liu, B. C. Church, and K. H. Sandhage, "Near net-shape/net-dimension $\mathrm{ZrC} / \mathrm{W}$-based composites with complex geometries via rapid prototyping and displacive compensation of porosity," Journal of the European Ceramic Society, vol. 30, no. 11, pp. 2265-2277, 2010.

[28] J. P. Kruth, P. Mercelis, J. van Vaerenbergh, L. Froyen, and M. Rombouts, "Binding mechanisms in selective laser sintering and selective laser melting," Rapid Prototyping Journal, vol. 11, no. 1, pp. 26-36, 2005.

[29] T. Hwa-Hsing, C. Ming-Lu, and Y. Hsiao-Chuan, "Slurrybased selective laser sintering of polymer-coated ceramic powders to fabricate high strength alumina parts," Journal of the European Ceramic Society, vol. 31, no. 8, pp. 1383-1388, 2011.

[30] G. V. Salmoria, R. A. Paggi, A. Lago, and V. E. Beal, "Microstructural and mechanical characterization of PA12/ MWCNTs nanocomposite manufactured by selective laser sintering," Polymer Testing, vol. 30, no. 6, pp. 611-615, 2011.

[31] D. Slavko and K. Matic, "Selective laser sintering of composite materials technologies," Annals of DAAAM \& Proceedings, p. p1527, 2010.

[32] Technology Gateway, "NASA- EBF3—electron beam form fabrication," 2009, http://www.youtube.com/watch?v= WrWHwHuWrzk.

[33] L. Murr, S. Gaytan, D. Ramirez et al., "Metal fabrication by additive manufacturing using laser and electron beam melting technologies," Journal of Materials Science \& Technology, vol. 28, no. 1, pp. 1-14, 2012.

[34] C. Semetay, Laser engineered net shaping (LENS) modeling using welding simulation concepts [ProQuest Dissertations and Theses], Lehigh University, 2007.

[35] Y. Xiong, Investigation of the laser engineered net shaping process for nanostructured cermets [ProQuest Dissertations and Theses], University of California, 2009.

[36] V. K. Balla, S. Bose, and A. Bandyopadhyay, "Processing of bulk alumina ceramics using laser engineered net shaping," International Journal of Applied Ceramic Technology, vol. 5, no. 3, pp. 234-242, 2008.

[37] Y. S. Liao, H. C. Li, and Y. Y. Chiu, "Study of laminated object manufacturing with separately applied heating and pressing," International Journal of Advanced Manufacturing Technology, vol. 27, no. 7-8, pp. 703-707, 2006.

[38] B. Vaupotic, M. Brezocnik, and J. Balic, "Use of PolyJet technology in manufacture of new product," Journal of Achievements in Materials and Manufacturing Engineering, vol. 18, no. 1-2, pp. 319-322, 2006.

[39] R. Singh, "Process capability study of polyjet printing for plastic components," Journal of Mechanical Science and Technology, vol. 25, no. 4, pp. 1011-1015, 2011.

[40] V. Petrovic, J. Vicente, H. Gonzalez et al., "Additive layered manufacturing: sectors of industrial application shown through case studies," International Journal of Production Research, vol. 49, no. 4, pp. 1061-1079, 2011.

[41] K. U. Bletzinger and E. Ramm, "Structural optimization and form finding of light weight structures," Computers and Structures, vol. 79, no. 22-25, pp. 2053-2062, 2001.

[42] A. Williams, "Architectural modelling as a form of research," Architectural Research Quarterly, vol. 6, no. 4, pp. 337-347, 2002.
[43] SweetOnionsCreations, "Architecture model and 3D printing-sweet onion creations," 2007, http://www.youtube.com/ watch? $\mathrm{v}=\mathrm{rEzugxybKmA}$.

[44] M. Phair, "Rapid prototyping: the next wave in architectural modeling," Building Design \& Construction, vol. 45, no. 11, pp. 15-16, 2004.

[45] I. Gibson, T. Kvan, and W. Ling, "Rapid prototyping for architectural models," Rapid Prototyping Journal, vol. 8, no. 2, pp. 91-99, 2002.

[46] J. Giannatsis, V. Dedoussis, and D. Karalekas, "Architectural scale modelling using stereolithography," Rapid Prototyping Journal, vol. 8, no. 3, pp. 200-207, 2002.

[47] F. Rengier, A. Mehndiratta, H. von Tengg-Kobligk et al., "3D printing based on imaging data: review of medical applications," International Journal of Computer Assisted Radiology and Surgery, vol. 5, no. 4, pp. 335-341, 2010.

[48] W. J. James, M. A. Slabbekoorn, W. A. Edgin, and C. K. Hardin, "Correction of congenital malar hypoplasia using stereolithography for presurgical planning," Journal of Oral and Maxillofacial Surgery, vol. 56, no. 4, pp. 512-517, 1998.

[49] Chaput, Christophe, and J. B. Lafon, "Ceramic industry," vol. 161, no. 9, pp. 15-16, 2011.

[50] G. Fielding, A. Bandyopadhyay, and B. Susmita, "Effects of silica and zinc oxide doping on mechanical and biological properties of 3D printed tricalcium phosphate tissue engineering scaffolds," Dental Materials, vol. 28, no. 2, pp. 113-122, 2012.

[51] J. Suwanprateeb, R. Sanngam, W. Suvannapruk, and T. Panyathanmaporn, "Mechanical and in vitro performance of apatite-wollastonite glass ceramic reinforced hydroxyapatite composite fabricated by 3D-printing," Journal of Materials Science, vol. 20, no. 6, pp. 1281-1289, 2009.

[52] R. Makovec, "Digital technologies in dental laboratories," Annals of DAAAM \& Proceedings, p. p1579, 2010.

[53] R. van Noort, "The future of dental devices is digital," Dental Materials, vol. 28, no. 1, pp. 3-12, 2012.

[54] A. Moscaritolo, "Woman receives 3D printer? created transplant Jaw," PC Magazine Online, 2012, http://www.pcmag .com/article2/0,2817,2399887,00.asp.

[55] S. J. Hollister, "Porous scaffold design for tissue engineering," Nature Materials, vol. 4, no. 7, pp. 518-524, 2005.

[56] M. A. Stoodley, J. R. Abbott, and D. A. Simpson, "Titanium cranioplasty using 3-D computer modelling of skull defects," Journal of Clinical Neuroscience, vol. 3, no. 2, pp. 149-155, 1996.

[57] N. Herbert, D. Simpson, W. D. Spence, and W. Ion, "A preliminary investigation into the development of 3-D printing of prosthetic sockets," Journal of Rehabilitation Research and Development, vol. 42, no. 2, pp. 141-146, 2005.

[58] B. Christensen, "New device prints human tissue," 2009, http://www.livescience.com/5977-device-prints-human-tissue.html.

[59] T. Qian and Y. Wang, "Micro/nano-fabrication technologies for cell biology," Medical and Biological Engineering and Computing, vol. 48, no. 10, pp. 1023-1032, 2010.

[60] S. J. Song, J. Choi, Y. D. Park et al., "Sodium alginate hydrogelbased bioprinting using a novel multinozzle bioprinting system," Artificial Organs, vol. 35, no. 11, pp. 1132-1136, 2011.

[61] V. Mironov, N. Reis, and B. Derby, "Bioprinting: a beginning," Tissue Engineering, vol. 12, no. 4, pp. 631-634, 2006.

[62] M. Conner, "3-D medical printer to print body parts," EDN, vol. 55, no. 3, p. 9, 2010.

[63] L. Zhao, V. Lee, S. Yoo, G. Dai, and X. Intes, "The integration of 3-D cell printing and mesoscopic fluorescence molecular 
tomography of vascular constructs within thick hydrogel scaffolds," Biomaterials, vol. 33, no. 21, pp. 5325-5332, 2012.

[64] "A step forward for artificial blood vessels," Expert Review of Cardiovascular Therapy 5.5, 817+, Academic OneFile, 2007.

[65] J. Thilmany, "Printed life: the 3-D printing of living organs for transplant isn't far-fetched, it's almost here," Mechanical Engineering-CIME, 44+, Academic OneFile, 2012.

[66] M. R. Dusseiller, D. Schlaepfer, M. Koch, R. Kroschewski, and M. Textor, "An inverted microcontact printing method on topographically structured polystyrene chips for arrayed micro-3-D culturing of single cells," Biomaterials, vol. 26, no. 29, pp. 5917-5925, 2005.

[67] R. D. Piner, J. Zhu, F. Xu, S. Hong, and C. A. Mirkin, “'Dippen' nanolithography," Science, vol. 283, no. 5402, pp. 661663, 1999.

[68] T. Wohlers, "Making products by using additive manufacturing," Manufacturing Engineering, vol. 146, no. 4, pp. 70-74, 2011.

[69] J. Malik, "Are 3D-printed fabrics the future of sustainable textiles?" in Ecouterre, 2010, http://www.ecouterre.com/ are?3d?printed?fabrics?the?future?of?sustainabletextiles/.

[70] F. Tortul, "3D printed shoes awarded most creative at Mittelmoda," in Freedom of Creation, 2010, http://www.freedomofcreation.com/for/3d-printed-shoes-awarded-mostcreative-at-mittelmoda.

[71] P. Wallich, “3-D Printers Proliferate [Hands On]," IEEE Spectrum, vol. 47, no. 9, p. 23, 2010.

[72] T. Bradshaw, "The printer that is transforming the world of creation," The Bath Chronicle, p. 45, 2011.

[73] M. Simkins, "3-D printing a goo goo: conceive and build your own tasty designs with sticky food or clay," Technology and Leanrning, p. 48, 2008.

[74] Singh and Sandeep, Beginning Google SketchUp for 3D Printing, Springer, 2010. 

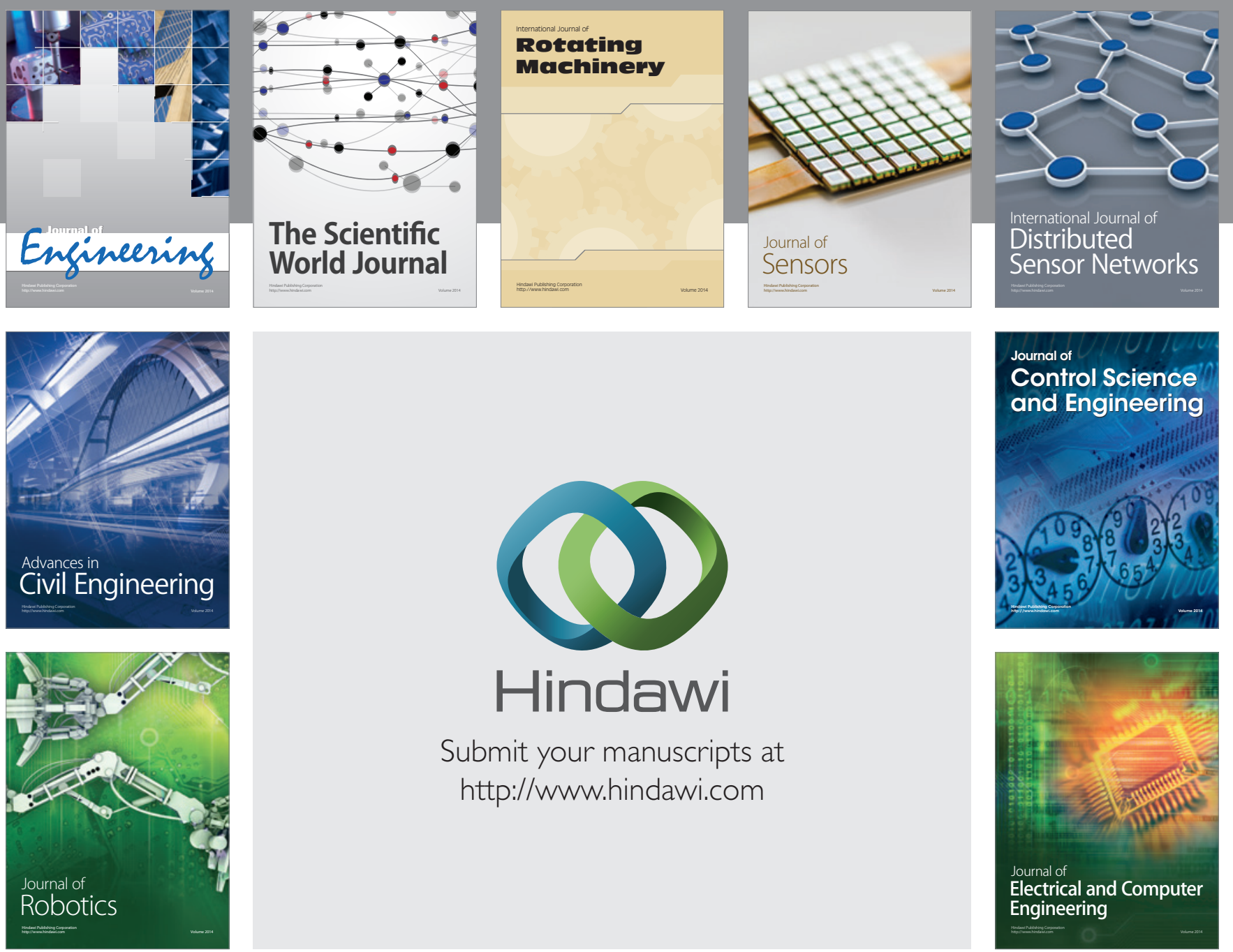

Submit your manuscripts at

http://www.hindawi.com
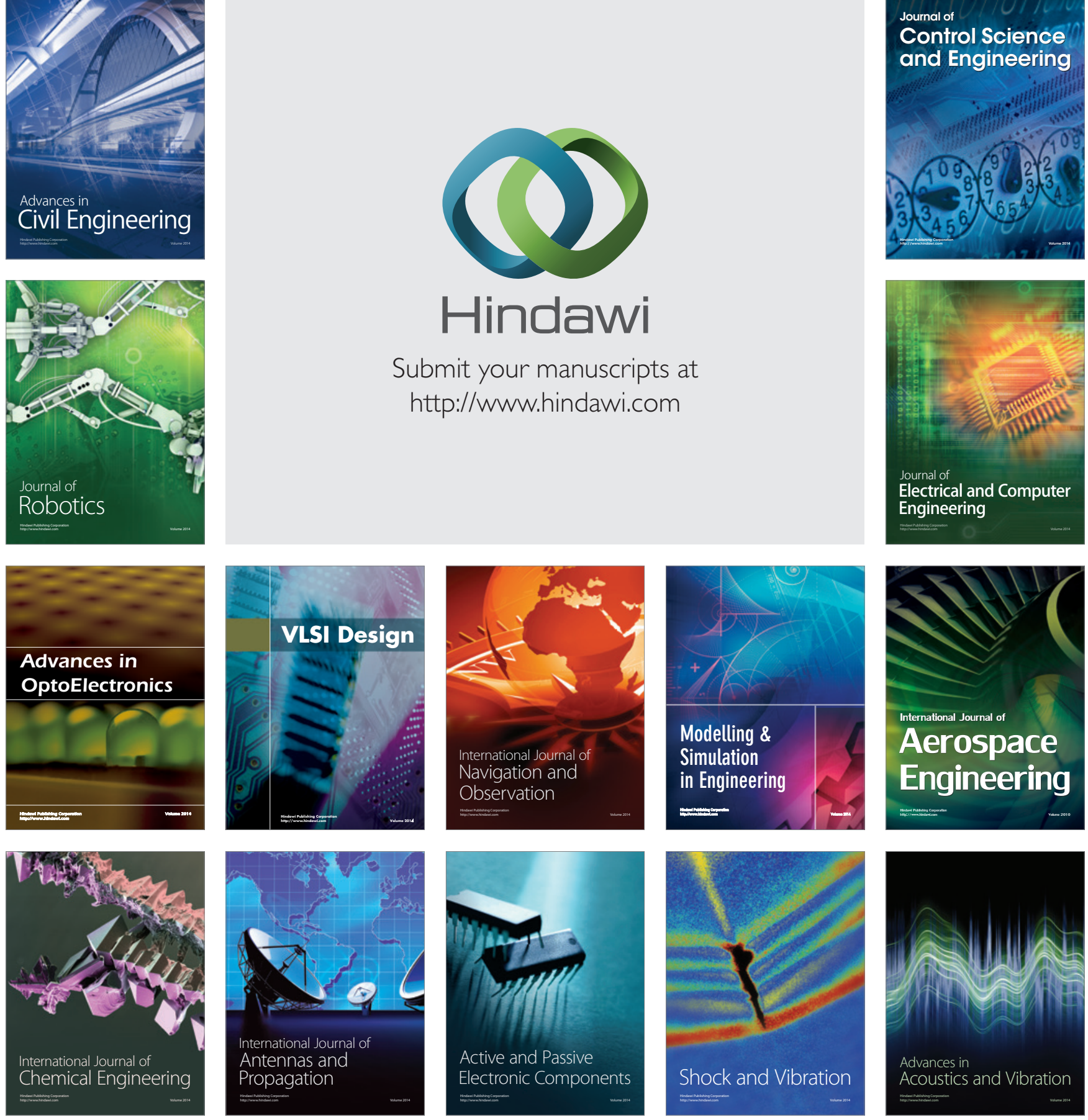